\title{
Countermeasures for Rural Vocational Education
}

\author{
Chen Mingjun ${ }^{1, ~ a, ~ L u o ~ F e n g l a n ~}{ }^{2, b}$ \\ ${ }^{1}$ Business School, Jiangxi Science and Technology Normal University \\ ${ }^{2}$ Business School, Jiangxi Science and Technology Normal University \\ a2943192684@qq.com, bluofl73@163.com
}

Keywords: Rural areas, Vocational education, Development.

\begin{abstract}
Under the background of today's society, China's rural vocational education still has problems such as insufficient and incomprehensive development. Based on the development of rural vocational education, China should increase investment in rural vocational education and promote the balanced development of rural vocational education. Accelerate vocational education system reform and promote the improvement of rural vocational education system in order to give full play to the importance role of rural vocational education in society, so that rural vocational education can provide talent support for better social development.
\end{abstract}

\section{Role and status of rural vocational education}

A large number of rural labor forces in China today have transferred to urban and non-agricultural employment. Rural labor is no longer just agricultural workers. A considerable part of rural labor force has become new industry employee, thus the strengthening of rural vocational education and training plays a very important role in the improvement of Chinese workers' quality, promoting urban and rural economic development, and promoting the transfer of rural labor force. These are prominent for social and economic development.

There are many constraints on the transfer of rural labor force. The quality of peasant's vocational education is an important factor in determining the scale and speed of transfer. On the one hand, with the development of social economy, all aspects of society have higher demands on the quality of labor. The shift sphere for low-quality labor force will become increasingly narrow, and rural labor force will only be able to move from low-productivity agricultural areas to higher-productivity areas if they have skills and achieve non-agricultural and urban flows. On the other hand, vocational education and training of farmers enable farmers to broaden their horizons, establish self-confidence and stimulate their initiative to non-agricultural industries and towns. In addition, the education level of rural labor force is obviously higher than the average educational level of rural labor force. Therefore, strengthening rural vocational education has an important impetus to promote the transfer of rural labor force.

The strengthening of rural vocational education is also a fundamental goal to promote farmers' income. Farmers' income mainly comes from agricultural income and labor income in two areas. Whether it is to improve agricultural production efficiency or to increase labor income, it is closely related with the quality of workers. Rural vocational education can improve the farmers' ability to practice and stimulate the creativity of farmers, and the basic measure to solve agricultural efficiency and farmers' income increases. It can be seen that strengthening rural vocational education has a significant effect on increasing farmers' income.

The strengthening of rural vocational education development is the need for modern new agricultural industry. The fundamental way of agriculture lies in science and technology and education. Farmers are the mainstay of agricultural production and an important carrier for successful transformation of agricultural science and technology. There are many factors involved in the modernization of agriculture, and the quality of human beings is the most fundamental factor. In the process of transition from traditional agriculture to modern agriculture, the technology 
provided by modern industry is applied to agriculture, and modern market economy concept and agriculture organization management both require high-quality farmers. At this stage, farmers of higher quality are in urgent need to improve agricultural level. However, current average education age of famers in China is less than seven years, and there are $80 \%$ of farmers with primary and junior high school education. Farmers with high school or higher education account for only a small part. Rural labor force who have received systematic agricultural vocational education are less than $10 \%$, so strengthening rural vocational education and improving scientific and cultural quality of farmers are the inevitable requirements for agricultural modernization.

\section{The practical significance of contemporary rural vocational education development}

The development of rural vocational education can greatly enhance the educational level of rural residents in China. The development of rural vocational education can improve their scientific and technological literacy and provide talents for the development of modern agriculture. At the same time, the construction of rural vocational education is an important guarantee for the development of modern agriculture. The development of modern agriculture requires a large number of knowledge-based and professional farmers' support. The farmers in new era should have professional knowledge and expertise and know how to operate and management. This is the fundamental guarantee for China's agricultural structure adjustment and the realization of modern agricultural production. The development situation of agriculture today is in regional layout upgrade. Improve the quality of agricultural products, combined with deep processing of agricultural products, constitutes a unified era of agricultural industrialization, but the development of modern agriculture needs professional rural workers.

The construction of new socialist countryside is the construction of rural social operation mechanism. The construction of spiritual civilization, the construction of life style, and the construction of rural economic structure. In the process of construction, rural vocational education disseminates scientific and technological knowledge and popularizes advanced culture, and in the meantime, it enhances the scientific and cultural literacy of farmers and constructs rural material civilization and spiritual civilization. Rural vocational education is also conducive to solving three rural issues, and rural vocational education can cultivate rural practical talents, provide agricultural services, so as to promote farmers to actively participate in democratic management, change farmers' bad habits in traditional life, build a positive and healthy lifestyle, and finally promote rural life, economic and culture.

Rural vocational education development is the transfer of rural labor demand. In recent years, the number of migrant workers in China has increased, and even become a special social group. According to relevant information, in 2010, the number of migrant workers in the country was 24300 people, and 154 million workers chose to be migrant workers. Migrant agricultural labor force was more than 42 million people in 2016. This large number of rural labor force is very unstable in the process of migrant employment. Due to their own cultural level and professional skills, they cannot get better development. It can be seen that the promotion of rural vocational education is an urgent need for the transfer of rural labor force. Only by carrying out large-scale training of rural vocational skills can we better solve the problems caused by the transfer of rural labor force.

\section{China's current rural vocational education development problems}

The old form of rural vocational education development does not meet modernization requirements. At present, the development of rural vocational education in China is mainly based on junior high school vocational education, and higher vocational education contains only a small proportion. This development structure is a serious tilt which does not suit modern and contemporary background. With the development of agricultural modernization industry, the overall quality of rural labor force also becomes higher, junior high school vocational education development model has been unable to adapt to the goal of modern development. At present, the 
healthy development model of rural vocational education in our country should be based on the vocational education of junior middle school, and gradually cultivate peasants' higher vocational education.

Government-based rural vocational education did not fully play its role. Rural vocational education needs to cultivate professional and technical farmers. The government should play a leading role in rural vocational education by promoting sustainable development of rural vocational education in order to make rural vocational education be recognized and to meet the social recognition of the new era's rural labor. In contemporary context, rural vocational education can make great contribution. But in fact, the government did not play full role as the main body of rural vocational education.

China's rural vocational education system is not systematic. The goal of agricultural modernization to rural vocational education is also multi-level and all-round. Lack of systematic design, rural vocational education cannot meet the needs of agricultural modernization in the process of China's rural vocational education reform. China's rural vocational education goals have not yet formed a clear direction, and the country's rural vocational education did not appear a wide range of choice path. Farmers did not get a wide range of employment options, which greatly reduced farmers' trust in rural vocational education. Systematic development of rural vocational education is conducive to guide rural vocational education to play a greater effect and has a catalytic role to achieve rural modernization.

The faculty of rural vocational education in our country is still insufficient. The faculty in rural vocational education is inadequate in China. In recent years, China's rural vocational education had slow development in the growth. In 2005-2015, full-time teachers in secondary vocational schools increased by only $27.11 \%$ in ten years, and the growth rate are very slow. But in contrast, secondary vocational school students had rapid expansion, resulting in uncoordinated proportion of teachers and students.

There are structural deficiencies in China's rural vocational education teachers. The practice guidance in rural vocational education is an important step in the process of rural vocational education. The demonstration operation of the instructor is helpful for the students to understand the knowledge correctly and improve practical skill level and comprehensive quality. However, the proportion of the number of teachers in basic courses, specialized courses and practice guidance courses in China's rural vocational education is seriously imbalanced, and the number of teachers instructing practice is seriously insufficient. Therefore, the shortage of internship instructors will seriously affect the quality of rural vocational education.

China's rural vocational education teachers are generally not in high level. Many teachers and parents who are engaged in rural vocational education are influenced by traditional social ideas and have the idea of "jumping from the farm". Their greatest ideal is to leave the countryside. Therefore, they do not want to encourage children to return to countryside for cause development, and do not want to engage in agriculture related work. Compared with higher education and general education, teachers in rural vocational schools are limited, which is also an important reason for the low level of teachers in rural vocational education.

\section{The development of vocational education under the background of contemporary society}

Increase investment in rural vocational education and promote vocational education to better serve the community. It is an effective way for the government to support agriculture, protect agriculture and enhance the international competitiveness of China's agriculture, which is a basic function of government service agriculture. Increase investment in rural vocational education, focus on solving three rural issues, and promote the development of rural vocational education and the development of agricultural modernization industry. Standing on the overall perspective, change the old vocational education a single development model through the careful development of development strategy. While increasing the investment in rural vocational education, rural vocational education should not simply develop agricultural vocational high school, but should develop a wide range of vocational education schools, so that rural vocational education really play 
a role in the transfer effect of rural surplus labor. And then through rural vocational education, better promote rural surplus labor force to achieve faster to the second and tertiary industries diversion to promote vocational education for better community service.

National rural vocational education planning will achieve the common development of regional rural vocational education. To improve the overall level of rural vocational education in China and accelerate the common development of rural vocational education in all regions of society, it is necessary to strengthen support for the areas where vocational education is relatively weak and promote the narrowing of development gap between regional and inter-school vocational education. Teacher allocation, teaching content, employment placement and other aspects of the overall consideration, the implementation of interrelated training methods promotes regional professional vocational education chain formation. To give full play to the students' advantages in central and western regions and professional practice and employment advantages in eastern region, we should provide new labor force to the development of vocational education in south and north of China and promote the development of rural vocational education throughout the country.

Speed up vocational education system reform to promote the improvement of rural vocational education system. China's vocational education development mechanism is not comprehensive and there is contradiction between supply and demand. We should optimize the professional and curriculum content set under the guidance of reasonable policy, highlighting the ability to improve the level of skills and professional ability of practice teaching. Train professional talents to adapt to production and professional job requirements, speed up the adjustment of rural vocational education structure, and form diversified, multi-level and multi-form rural vocational education system. Its education hierarchy, personnel training structure and education type structure need to meet the development needs of modern economy structure so as to improve the quality and efficiency of education. China should mobilize social resources in a comprehensive way under the guidance of reasonable policy. With the help of educational policies and other means, adjust social forces and improve vocational education school mechanism to speed up the reform and innovation of vocational education system and mechanism to promote rural vocational school system and rural vocational education system.

Make full use of modern technology and increase rural remote education use. Modern rural vocational education should conform to the trend of modern agriculture, and use modern technology to construct flexible rural distance education mode. First, you can use mobile phones and other new media and convenient technology to build rural vocational education's mobile learning model to create a flexible learning characteristics; Second, pay attention to the practicality of curriculum set and set different characteristics of learning courses for different regions' farmers; Third, form a multi-faceted and multi-level cooperation including government, enterprises, rural vocational and technical institutions, farmers, human resources and social security to achieve resource sharing, build mutual assistance, and build stable and integrate relationship.

Mobilize the enthusiasm of rural residents to receive vocational education. Rural residents are the main body of rural vocational education. Rural residents' recognition and acceptance are the basic standard of rural vocational education success. To mobilize the enthusiasm of rural residents to participate in vocational education, first of all, select rural residents needing educational content. Current characteristics are ecology, benefits, tourism agriculture and organic agriculture practical technology, and vocational skills for farmers to work in city. To choose educational methods to facilitate rural residents to learn, education and training should be as close as possible to the practice of rural residents, preferably combined with the productive work of rural residents and combined with the transfer of labor output. In the popularization of agricultural technology, establish the necessary system norms in rural residents' vocational education, including educational institutions charges, quality, employment transfer, and participation of rural residents to participate in preferential treatment and so on. We should pay attention to carry out extensive publicity and mobilization to improve the enthusiasm of farmers to learn professional and technical skills so that the future rural labor force can grasp the occupation with suitable practical skills. 


\section{References}

[1] Xu Zuqin. Measures to strengthen peasant workers' community construction education [J]. Modern Vocational Education, 2015(24).

[2] Shang Xuefang, Jiang Weiliang, Zheng Shiying.Study on the problems in rural vocational education [J]. Journal of Shandong Agricultural University (Social Science Edition), 2011(1).

[3] Lu Yong. Develop rural vocational education toserveagricultural modernization [J]. Agricultural Education Research, 2011(4).

[4] Liu Ying, Yang Mengdi. The bottleneck and outlet of sustainable development of rural vocational education [J] Vocational and Technical Education, 2015(18).

[5] Liu Yuan. Understand the new stage of modern vocational education system development ----Talk about the development of the 18th National Congress of the Communist Party of China and the development of vocational education [J]. Journal of Tianjin Vocational and Technical College, 2013 (12). 